\title{
Vitamin D status in female military personnel during combat training
}

\author{
Nancy E Andersen', J Philip Karl', Sonya J Cable², Kelly W Williams², Jennifer C Rood ${ }^{3}$, Andrew J Young ${ }^{1}$, \\ Harris R Lieberman', James P McClung ${ }^{1 *}$
}

\begin{abstract}
Vitamin $D$ is an essential nutrient for maintaining bone health. Recent data suggest that vitamin $D$ and calcium supplementation might affect stress fracture incidence in military personnel. Although stress fracture is a health risk for military personnel during training, no study has investigated changes in vitamin D status in Soldiers during United States (US) Army basic combat training (BCT). This longitudinal study aimed to determine the effects of BCT on 25-hydroxyvitamin D (25(OH)D) and parathyroid hormone (PTH) levels in female Soldiers. Serum 25(OH)D and PTH were assessed in 74 fasted Soldier volunteers before and after an 8-week BCT course conducted between August and October in Columbia, South Carolina. In the total study population, 25(OH)D levels decreased (mean \pm SD) from $72.9 \pm 30.0$ to $63.3 \pm 19.8 \mathrm{nmol} / \mathrm{L}(P<0.05)$ and PTH levels increased from $36.2 \pm 15.8$ to $47.5 \pm 21.2 \mathrm{pg} / \mathrm{mL}$ $(P<0.05)$ during BCT. Ethnicity affected changes in vitamin $D$ status (ethnicity-by-time interaction, $P<0.05) ; 25(\mathrm{OH})$ $D$ decreased $(P<0.05)$ in both Hispanic and non-Hispanic whites, but did not change in non-Hispanic blacks. Ethnicity did not affect BCT-induced changes in PTH. These data indicate that vitamin D status in female Soldiers may decline during military training in the late summer and early autumn months in the Southeastern US. Future studies should strive to determine the impact of military clothing and seasonality on vitamin D status, as well as the functional impact of declining vitamin D status on bone health.
\end{abstract}

\section{Introduction}

Vitamin D is an essential nutrient for maintaining bone health. Sufficient levels of vitamin D, assessed by measuring 25-hydroxyvitamin D $(25(\mathrm{OH}) \mathrm{D})$ concentrations, can be defined as the $25(\mathrm{OH}) \mathrm{D}$ concentration that either prevents an increase in parathyroid hormone (PTH), a serum calcium regulator suppressed by $25(\mathrm{OH}) \mathrm{D}$, or optimizes calcium absorption [1]. Vitamin D sufficiency may prevent fractures in adults, while insufficiency may result in poor bone mineralization, pain, and rickets in children [2]. According to data collected in the third National Health and Nutrition Examination Survey (NHANES III), women aged 14-30 years in the United States (US) consume less vitamin D from dietary and supplemental sources than other age groups [3]. Suboptimal vitamin D intake and diminished vitamin D status may be particularly important during periods of intense physical activity such as military training, as compromised bone health could contribute to

\footnotetext{
* Correspondence: james.mcclung3@us.army.mil

'Military Nutrition Division, US Army Research Institute of Environmental Medicine, Natick, MA, 01760, USA

Full list of author information is available at the end of the article
}

the development of stress fractures. Decrements in nutritional status during US Army basic combat training (BCT) have been documented in female Soldiers [4]. As over 300,000 women serve in the US military, understanding the specific nutritional needs of this population during physical training is critical.

Poor vitamin D status has been associated with an increased incidence of stress fracture in Soldiers [5]. Stress fractures are one of the most debilitating injuries in military recruits, and occur most often in military personnel beginning exercise regimens that include unaccustomed and physically-demanding activities. During military training regimens such as BCT, up to $21 \%$ of female recruits are diagnosed with at least one stress fracture [6]. The impact of stress fractures on military readiness is notable; the attrition rate of female Soldiers with diagnosed stress fractures may be up to $60 \%[6,7]$.

Exploring the effects of $\mathrm{BCT}$ on vitamin D status in female Soldiers may contribute to the development of improved guidance regarding sunlight exposure and dietary vitamin D intake for stress fracture prevention.

\section{() Biomed Central}


The objective of this pilot study was to investigate the effects of military training on vitamin D status and $\mathrm{PTH}$, an indirect vitamin D status indicator, in female military personnel [8]. Previous studies indicate differences in both stress fracture prevalence and vitamin D status between ethnicities [6,9]. Therefore, a secondary objective was to examine the relationship between vitamin D and PTH levels and ethnicity.

\section{Methods}

Volunteers were recruited from a population of female Soldiers entering US Army BCT at Fort Jackson, Columbia, SC. This study was approved by the Human Use Review Committee at the US Army Research Institute of Environmental Medicine (USARIEM). Human volunteers participated in these studies after providing their free and informed voluntary consent. Investigators adhered to Army Regulation 70-25 and US Army Medical Research and Materiel Command Regulation 70-25 on the use of volunteers in research. The training course was conducted over an 8-week period between August and October of 2007. The data presented in this short report were collected as a subset of a previously published randomized, placebo-controlled trial designed to determine the role of iron status for maintaining health and performance during BCT $[10,11]$. The cohort examined in this analysis consumed placebo capsules containing cellulose each day; these volunteers were not provided with iron containing capsules nor did they have access to other dietary supplements. From the initial study $[10,11]$, blood samples were available for the assessment of vitamin D status and PTH levels from 74 volunteers (Table 1).

Basic combat training consists of both physical and military-specific training. The course is divided into three phases. The first phase consists of physical training and learning Army values and policies. The second phase involves weapons training and various assault courses. The final phase involves field exercises and the evaluation of skills taught during the first two phases. Physical training activities during BCT include road marching, distance running, and sprinting. Soldiers also participate in muscle strength training activities,

Table 1 Volunteer demographics 1

\begin{tabular}{lll}
\hline Age $(\mathrm{yrs})$ & $\frac{\text { Pre }}{21 \pm 4}$ & $\underline{\text { Post }}$ \\
Height $(\mathrm{cm})$ & $162 \pm 6$ & \\
Weight $(\mathrm{kg})$ & $62 \pm 9$ & $62 \pm 7$ \\
Ethnicity (n) & & \\
$\quad$ Non-Hispanic whites & 39 & \\
$\quad$ Non-Hispanic blacks & 24 & \\
Hispanic whites & 11 & \\
\hline
\end{tabular}

${ }^{1}$ Data collected during the initial (pre) and final (post) wks of basic combat training; means $\pm \mathrm{SD}$. including calisthenics, sit-ups, and push-ups. Military activities include obstacle courses, didactic classroom instruction, and standing in formation [11]. Comprehensive measures of the ambulatory activity experienced during $\mathrm{BCT}$ have been reported elsewhere [12]. During physical training activities, which typically occur in the early morning (0500-0700) hours, Soldiers are required to wear uniforms consisting of shorts and short-sleeved shirts. At all other times Soldiers are generally required to wear the Army Combat Uniform (ACU), which consists of boots, long pants, long-sleeved shirts, and caps. While wearing the ACU, only the hands and face are exposed to sunlight. Although the use of sun protection is recommended during $\mathrm{BCT}$, data regarding the use of such products was not collected during this study.

Blood was collected from fasted Soldiers by antecubital venipuncture, processed on site, frozen, and shipped to USARIEM or the Pennington Biomedical Research Center (Baton Rouge, LA) for further analysis. Serum 25 $(\mathrm{OH}) \mathrm{D}$ (Immunodiagnostic Systems, Fountain Hills, AZ) and PTH (Siemens 2000, Los Angeles, CA) levels were determined using commercially available immunoassays. Self-reported ethnic characteristics were used to separate subjects into 3 groups (non-Hispanic white, $\mathrm{n}=39$; non-Hispanic black, $\mathrm{n}=24$; Hispanic white, $\mathrm{n}=11$ ) for statistical analysis.

Statistical analysis was performed using the Statistical Package for the Social Sciences v. 15.0 (SPSS Inc., Chicago, IL). A two-factor ANOVA with repeated measures was used to test for main effects of both ethnicity and time, as well as ethnicity-by-time interactions in 25 $(\mathrm{OH}) \mathrm{D}$ and PTH. When a significant ethnicity-by-time interaction was observed, post hoc analyses with Bonferroni adjustments were conducted to identify withinand between-group differences. Significance was set at $P \leq 0.05$ for all tests.

\section{Results}

Overall, mean 25(OH)D levels declined during BCT $(72.9 \pm 30.0$ vs $63.3 \pm 19.8 \mathrm{nmol} / \mathrm{L}, P<0.05$, Figure $1 \mathrm{~A})$. Ethnicity affected changes in vitamin $\mathrm{D}$ status (ethnicity-by-time interaction, $P<0.05)$; 25(OH)D decreased $(P<0.05)$ in non-Hispanic whites, and in Hispanic whites, but did not change in non-Hispanic blacks (Figure 2A). Furthermore, mean 25(OH)D levels were lowest $(P<0.05)$ in non-Hispanic blacks at both time points. In the total study population, PTH levels increased over the course of BCT (36.2 \pm 15.8 vs 47.5 $\pm 21.2 \mathrm{pg} / \mathrm{mL}, P<0.05$, Figure $1 \mathrm{~B}$ ); however, this change was independent of ethnicity (Figure 2B).

\section{Discussion}

Vitamin D is a critical nutrient for active populations, as it contributes to effective bone remodeling and calcium 

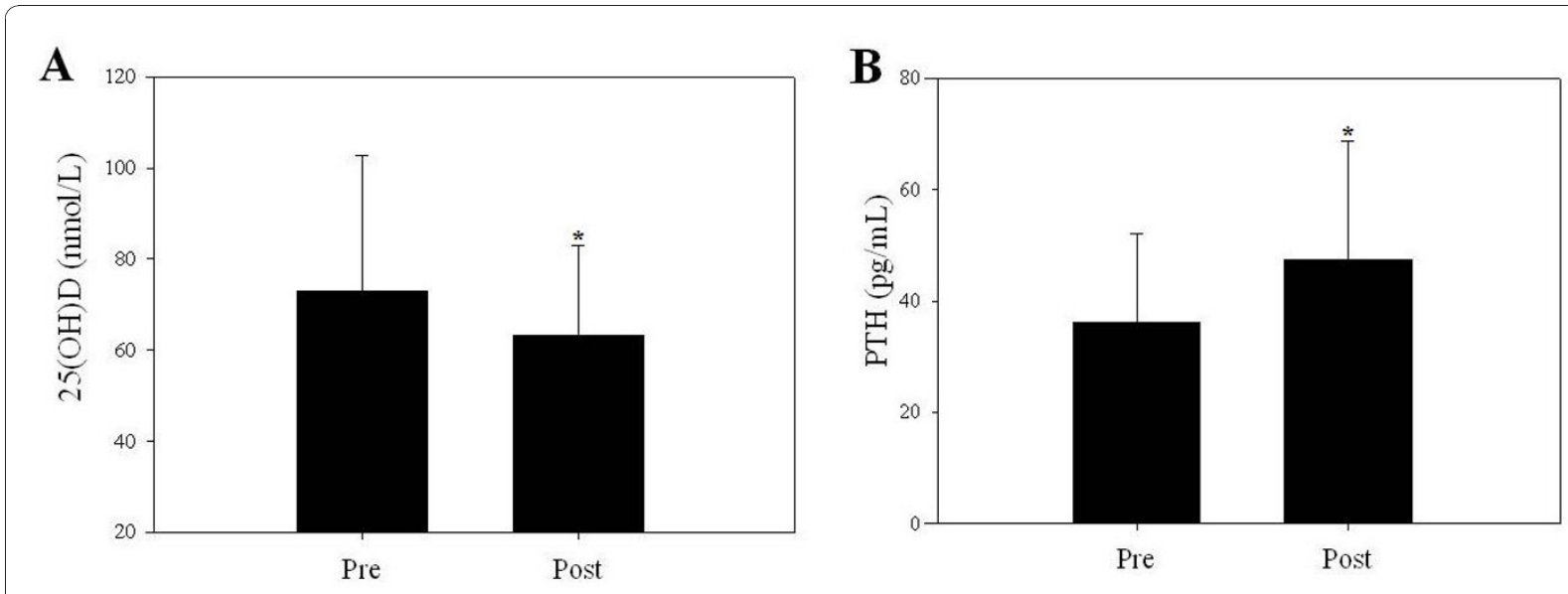

Figure 1 (A) Mean serum 25-hydroxyvitamin and (B) parathyroid hormone levels in female Soldiers pre- and post-basic combat training. Serum 25-hydroxyvitamin D, 25(OH)D; parathyroid hormone, PTH. $n=74$; values are means \pm SD. Asterisks $\left(^{*}\right)$ indicate significant differences $(P<0.05)$ from pre-values.

homeostasis. The major finding of this pilot study is that vitamin D status in female Soldiers declines during military training in the summer and early autumn months in the Southeastern US. This finding was unanticipated, as we expected the vitamin D status of female Soldiers to remain static or increase due to sunlight exposure during $\mathrm{BCT}$, as much of the training occurs outdoors during daylight hours. Although further research is required to elucidate the mechanism, we hypothesize that the type of clothing worn during $\mathrm{BCT}$, coupled
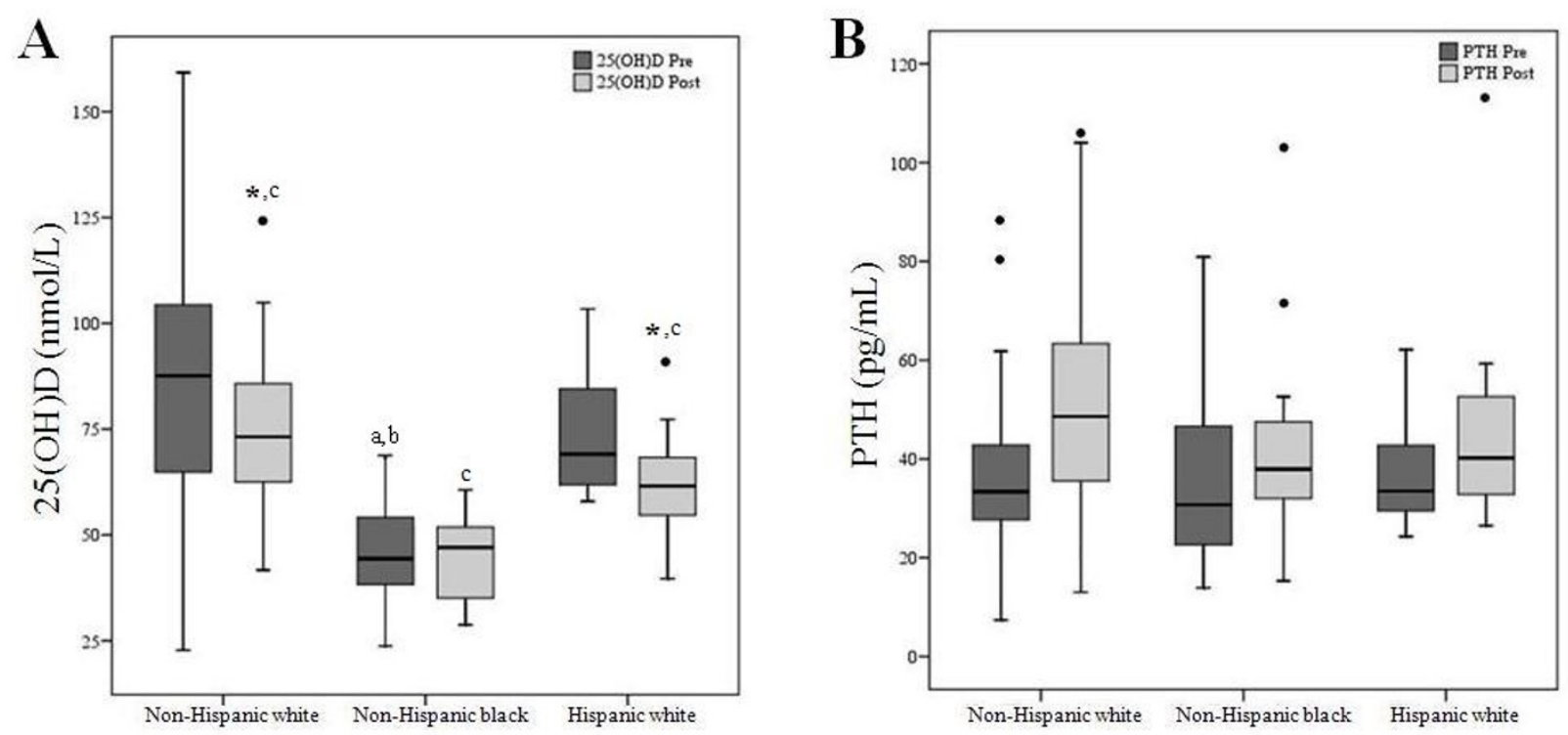

Figure 2 (A) Boxplots of serum 25-hydroxyvitamin D and (B) parathyroid hormone levels in female Soldiers pre- and post-basic combat training by ethnicity. Serum 25-hydroxyvitamin D, 25(OH)D; parathyroid hormone, PTH; basic combat training, BCT. $n=74$; nonHispanic white, $n=39$; non-Hispanic black, $n=24$; Hispanic white, $n=11$. Boxes represent the middle $50^{\text {th }}$ percentile, and vertical lines extend to the $10^{\text {th }}$ and $90^{\text {th }}$ percentiles. Median values are marked by a line within each box. Values below the $10^{\text {th }}$ percentile or above the $90^{\text {th }}$ percentile are identified by solid circles (•). A two-factor repeated measures ANOVA with Bonferroni adjustments was utilized to determine the effects of time and ethnicity on $25(\mathrm{OH}) \mathrm{D}$ and PTH levels. Asterisks $\left(^{*}\right)$ indicate significant differences between mean values pre- and post-BCT within ethnicities $(P<0.05)$. ${ }^{a}$ differences between mean values of non-Hispanic whites and non-Hispanic blacks pre-BCT $(P<0.01)$; ${ }^{b}$ differences between mean values of non-Hispanic blacks and Hispanic whites pre-BCT $(P<0.05)$; ${ }^{c}$ differences between mean values of all ethnic groups post-BCT $(P<0.05)$. 
with potentially inadequate dietary vitamin D intake may contribute to the observed decline in vitamin $\mathrm{D}$ status. Recent studies have utilized $25(\mathrm{OH}) \mathrm{D}$ values of $\leq 75$ $\mathrm{nmol} / \mathrm{L}$ as an indicator of suboptimal vitamin $\mathrm{D}$ status $[8,13,14]$. If this cutoff is applied to the data gleaned from the present study, $57 \%$ of subjects entered BCT with $25(\mathrm{OH}) \mathrm{D}$ levels $<75 \mathrm{nmol} / \mathrm{L}$, and $75 \%$ completed BCT below the cutoff value, indicating that the majority of Soldiers demonstrated suboptimal vitamin D status during BCT.

Our findings demonstrate ethnic differences in vitamin D status. Similar to previous reports, 25(OH)D levels were lowest in non-Hispanic blacks and tended to be highest in non-Hispanic whites [15-17]. Furthermore, vitamin D status declined significantly in non-Hispanic and Hispanic whites, but not in non-Hispanic blacks. We observed an increase in PTH levels within the total study population; however, PTH levels did not differ between ethnic groups. Although some studies have demonstrated higher PTH levels in blacks, this relationship appears to be inconsistent $[15,17]$. It is possible that physical activity associated with BCT had an interactive effect on vitamin $\mathrm{D}$ and PTH levels, as others have described complex relationships between physical activity, vitamin D status, PTH levels, and bone health [18,19].

To the best of our knowledge, this preliminary study is the first to describe a decline in vitamin D status in female military personnel during US Army training. Limitations of our study include a lack of data regarding the use of sun protection and the collection of data during only one cycle of BCT which occurred during the late summer and early autumn months. Future studies should aim to investigate the health and functional consequences of this decline, especially in relation to effects on bone strength and stress fracture incidence and its mechanism, as declines in vitamin D status may negatively influence calcium absorption and compromise bone health. For this reason, vitamin $\mathrm{D}$ and calcium supplementation may prove efficacious for preventing stress fracture during military training or other physical training regimes [20]. Dietary intake assessment may help to illustrate the nutritional factors contributing to changes in vitamin D status during training and differences between ethnic groups, and may also provide support for recommending nutrition education or intervention during BCT. Furthermore, future studies should assess the effects of military uniforms coupled with the seasonal nature of changes in vitamin D status during military training.

\section{Acknowledgements}

This work was supported by the US Army Medical Research and Materiel Command. The authors wish to acknowledge the Soldier volunteers that participated in this study as well as the command staff at Fort Jackson, SC, for allowing access to Soldiers. Portions of this manuscript were presented in abstract form at Experimental Biology 2010, Anaheim, CA, April 24-28. The opinions or assertions contained herein are the private views of the authors and are not to be construed as official or as reflecting the views of the Army or the Department of Defense. Any citations of commercial organizations and trade names in this report do not constitute an official Department of the Army endorsement of approval of the products or services of these organizations.

\section{Author details}

${ }^{1}$ Military Nutrition Division, US Army Research Institute of Environmental Medicine, Natick, MA, 01760, USA. Experimentation and Analysis Element, Directorate of Basic Combat Training, Fort Jackson, SC, 29207, USA.

${ }^{3}$ Pennington Biomedical Research Center, Louisiana State University System, Baton Rouge, LA, 70808, USA.

\section{Authors' contributions}

All authors read and approved the final manuscript. NA and JK participated in data collection, statistical analysis, and manuscript preparation. SC, KW, and JR participated in data collection and study management. HL and AY contributed to study design and manuscript preparation. JM served as the principal investigator and contributed to study design, data collection, and manuscript preparation. All authors read and approved the final draft.

\section{Competing interests}

The authors declare that they have no competing interests.

Received: 8 September 2010 Accepted: 14 December 2010 Published: 14 December 2010

\section{References}

1. Aloia JF, Chen DG, Yeh JK, Chen H: Serum vitamin D metabolites and intestinal calcium absorption efficiency in women. Am J Clin Nutr 2010, 92:835-40.

2. Moore CE, Murphy MM, Holick MF: Vitamin D intakes by children and adults in the United States differ among ethnic groups. J Nutr 2005, 135:2478-2485.

3. Moore C, Murphy MM, Keast DR, Holick MF: Vitamin D intake in the United States. J Am Diet Assoc 2004, 104:980-983.

4. McClung JP, Karl JP, Cable SJ, Williams KW, Young AJ, Lieberman HR: Longitudinal decrements in iron status during military training in female soldiers. Br J Nutr 2009, 102:605-609.

5. Ruohola JP, Laaksi I, Ylikomi T, Haataja R, Mattila VM, Sahi T, Tuohimaa P, Pihlajamaki $\mathrm{H}$ : Association between serum 25(OH)D concentrations and bone stress fractures in Finnish young men. J Bone Miner Res 2006, 21:1483-1488.

6. Jones BH, Thacker SB, Gilchrist J, Kimsey CD Jr, Sosin DM: Prevention of lower extremity stress fractures in athletes and soldiers: a systematic review. Epidemiol Rev 2002, 24:228-247.

7. Friedl KE, Evans RK, Moran DS: Stress fracture and military medical readiness: bridging basic and applied research. Med Sci Sports Exerc 2008, 40(Suppl 11):S609-S622.

8. Vieth $\mathrm{R}$, Cole DE, Hawker GA, et al: Wintertime vitamin D insufficiency is common in young Canadian women, and their vitamin D intake does not prevent it. Eur J Clin Nutr 2001, 55:1091-1097.

9. Harris SS: Vitamin D and African Americans. J Nutr 2006, 136:1126-1129.

10. Karl JP, Lieberman HR, Cable SJ, Williams KW, Glickman EL, Young AJ, McClung JP: Poor iron status is not associated with overweight or overfat in non-obese pre-menopausal women. J Am Coll Nutr 2009, 28:37-42.

11. McClung JP, Karl JP, Cable SJ, Williams KW, Nindl BC, Young AJ, Lieberman HR: Randomized, double-blind, placebo-controlled trial of iron supplementation in female soldiers during military training: effects on iron status, physical performance, and mood. Am J Clin Nutr 2009, 90:1-8.

12. Knapik JJ, Darakjy S, Hauret KG, Canada S, Marin R, Jones BH: Ambulatory physical activity during United States Army Basic Combat Training. Int J Sports Med 2007, 28:106-115.

13. Vieth R, Bischoff-Ferrari , Boucher BJ, Dawson-Hughes B, Garland CF, Heaney RP, Holick MF, Hollis BW, Lamberg-Allardt C, McGrath JJ, Norman AW, Scragg R, Whiting SJ, Willett WC, Zittermann A: The urgent need to recommend an intake of vitamin D that is effective. Am J Clin Nutr 2007, 85:649-650. 
14. Dawson-Hughes B, Heaney RP, Holick MF, Lips P, Meunier PJ, Vieth R: Estimates of optimal vitamin D status. Osteoporos Int 2005, 16:713-716.

15. Looker AC, Dawson-Hughes B, Calvo MS, Gunter EW, Sahyoun NR: Serum 25-hydroxyvitamin $D$ status of adolescents and adults in two seasonal subpopulations from NHANES III. Bone 2002, 30:771-777.

16. Nesby-O'Dell S, Scanlon KS, Cogswell ME: Hypovitaminosis D prevalence and determinants among African American and white women of reproductive age: third National Health and Nutrition Examination Survey, 1988-1994. Am J Clin Nutr 2002, 76:187-192.

17. Dawson-Hughes B: Racial/ethnic considerations in making recommendations for vitamin $\mathrm{D}$ for adult and elderly men and women. Am J Clin Nutr 2004, 80(Suppl 6):S1763-S1766.

18. Constantini NW, Dubnov-Raz G, Chodik G, Rozen GS, Giladi A, Ish-Shalom S: Physical activity and bone mineral density in adolescents with vitamin $D$ deficiency. Med Sci Sports Exerc 2009.

19. Foo LH, Zhang Q, Zhu K, Ma G, Trube A, Greenfield H, Fraser DR: Relationship between vitamin D status, body composition and physical exercise of adolescent girls in Beijing. Osteoporos Int 2009, 20:417-425.

20. Lappe J, Cullen D, Haynatzki G, Recker R, Ahlf R, Thompson K: Calcium and vitamin $D$ supplementation decreases incidence of stress fractures in female navy recruits. J Bone Miner Res 2008, 23:741-749.

doi:10.1186/1550-2783-7-38

Cite this article as: Andersen et al:: Vitamin D status in female military personnel during combat training. Journal of the International Society of Sports Nutrition 2010 7:38.

\section{Submit your next manuscript to BioMed Central} and take full advantage of:

- Convenient online submission

- Thorough peer review

- No space constraints or color figure charges

- Immediate publication on acceptance

- Inclusion in PubMed, CAS, Scopus and Google Scholar

- Research which is freely available for redistribution

Submit your manuscript at www.biomedcentral.com/submit 